ORIGINAL ARTICLE

\title{
Disability and risk of school related injury
}

\author{
M Ramirez, C Peek-Asa, J F Kraus
}

Injury Prevention 2004;10:21-26. doi: 10.1136/ip.2003.002865

See end of article for authors' affiliations

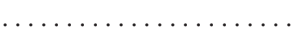

Correspondence to: Dr Marizen Ramirez, Division of Research on Children, Youth and Families, Childrens Hospital Los Angeles, 4650 Sunset Blvd MS\#30, Los Angeles, CA 90027, USA; MarizenRamirez@ chla.usc.edu

\begin{abstract}
Objective: Approximately six million children with disabilities attend school in the United States. Cognitive and physical limitations may compromise their ability to handle environmental hazards and hence increase their risk for injury. The objective of this study was to describe the epidemiology of school related injury among children enrolled in 17 special education schools in one large, urban school district.

Design: Altogether 6769 schoolchildren with disabilities were followed up from 1994-98. Injury and population data were collected from pupil accident reports and existing school records. Associations were estimated through generalized estimating equations.

Results: A total of 697 injuries were reported for a rate of 4.7/100 students per year. Children with multiple disabilities had a $70 \%$ increased odds of injury compared with the developmentally disabled (odds ratio (OR) 1.7, 95\% confidence interval (CI) 1.3 to 2.3). The physically disabled (OR $1.4,95 \% \mathrm{Cl} 1.0$ to 1.9) had a modest increased odds of injury. Cuts, bruises, and abrasions composed almost three fourths of all injuries; almost half of these injuries were to the face. Falls (34\%) and insults by other students (31\%) were the most common external causes. More than a fourth of injuries were sports related, and $21 \%$ occurred on the playground/athletic field. Injury patterns differed across disabilities.

Conclusions: Although limited to one school district, the population studied is the largest cohort thus far of schoolchildren with disabilities. With this large study base, potentially high risk groups were identified and circumstances of injury described. This information is imperative for developing and improving school based injury prevention measures.
\end{abstract}

O ne in every 10 children worldwide has one or more serious disabilities (www.disabilityworld.org/0608_03/children/unicef.shtml, accessed 2003). By definition, children with disabilities have some reduced ability to conduct activities and social functions at school and play. ${ }^{12}$ Disabilities involve neurologic, orthopedic, or cognitive impairments that may adversely affect development and educational performance. ${ }^{2}$ Consequently, United States legislation, like the Elementary and Secondary Education Act and Individuals with Disability Education Act, mandate environmental and medical provisions for educating children with disabilities (www.ed.gov/offices/osers/idea/the law. html, accessed 2000). In 2001, six million students utilized special services to attend school and each year their enrollment increases. ${ }^{34}$

Creating safe and accessible school facilities is challenging. ${ }^{5}$ Campuses, called special education schools, incorporate structural modifications such as wheelchair ramps, wide doors, and elevators. Even with these features, those with disabilities may be at high risk of injury. Language, cognitive, and motor skill limitations could complicate the processing of physical hazards at school. ${ }^{67}$

Designing suitable school environments for these children is further complicated by their varying functional levels. Autistic and deaf children, for example, differ in their behavioral, social, and physical capacities. This may lead to differential risk of injury, but risk in this population has neither been measured nor compared.

Research on school based injury among disabled children is limited to few reports. The National Pediatric Trauma Registry reported that youth with disabilities sustain $17 \%$ of all school related injuries but represent fewer than $2 \%$ of the student population of the United States. ${ }^{38}$ Woringer from Switzerland reported high injury rates in "special" classes of developmentally disabled students. ' Handicapped schoolchildren in Africa had higher rates of dental injury than able bodied students. ${ }^{10}$
Studies in non-school settings have been more informative. Disabled children had higher rates of injury than nondisabled children in a study of daycare injuries and an analysis of the 1988 United States National Health Interview Survey. ${ }^{611}$ A report of home injuries treated in a Belgian hospital described injuries to children with varying mental disabilities. ${ }^{12}$ Most injuries were to the head, suffered by children with epilepsy and cerebral palsy. Higher rates of injury hospitalization were reported among young persons with intellectual disability compared with the general population in Australia. ${ }^{13}{ }^{14}$ It is unknown if these injuries occurred at school, a place where children with disabilities do spend a substantial amount of their waking hours.

These research gaps prompted us to study injury among children in special education. Schools are an ideal setting for an epidemiologic study. The growing number of disabled children attending school provides a large, well defined cohort. In contrast to diverse home settings, schools are a controlled environment to examine incidence and risk factors. Furthermore, schools provide an opportunity to introduce countermeasures during activities like organized recreation or structured lesson time.

We addressed the following objectives: (1) measure the rate of injury among students with disabilities; (2) describe the nature and characteristics of school injuries; and (3) compare risk of injury by various disabling conditions.

\section{METHODS \\ Study population}

We followed up students from 17 of 18 special education schools in the Los Angeles Unified School District (LAUSD)

Abbreviations: CDC, Centers for Disease Control and Prevention; $\mathrm{Cl}$, confidence interval; GEE, generalized estimating equations; LAUSD, Los Angeles Unified School District; OR, odds ratio 
from the 1994-98 academic years. One excluded school services homebound students with severe medical needs.

\section{Definitions and variables}

An injury case was defined as physical trauma to any disabled student sustained during a school sponsored activity. We identified and collected details of injuries (nature, cause, location, activity) from pupil accident reports completed by school staff.

We linked cases to disability, age, gender, and race/ ethnicity data from the Information Technology Division. To classify disability, a team of experts used the following categories defined by the California Department of Education: aphasic, autistic, blind, deaf/blind, developmentally disabled, mentally retarded, established medical disability, hard of hearing, language/speech impaired, learning disabled, multidisabled, other health, orthopedic, partially sighted, seriously emotionally disturbed, and traumatic brain injured. ${ }^{15}$ Developmentally disabled are lowest functioning with severe, lifelong mental and/or physical disability. Multiple disabled students have more than one diagnosed disability. ${ }^{15}$

Disabilities were collapsed into five broader groups due to limited person-time and few injury cases observed in most individual disability types. These categories reflect similar physical and cognitive limitations: (1) developmentally disabled; (2) emotional/mental disabled (autistic, learning disabled, mentally retarded, and emotionally disturbed); (3) physically/sensory disabled (orthopedic, aphasic, blind, deaf/ blind, hard of hearing, language/speech impaired, partially sighted); (4) multidisabled; and (5) other disabled (established medical disability, other health impaired, undetermined disability, and traumatically brain injured).

We used the primary cause in the chain of events to describe the external cause. For example, if a child first collided with a pole and then fell, the primary cause was a collision. Because of the limited cognition of many subjects, we did not ascertain intentionality. Assault such as bites, pushes, or kicks were labeled "injuries by other students".

The population was identified and quantified using yearly enrollment rosters. We accrued student-years and corrected for absenteeism by multiplying by ( 1 -average absentee rate) for each school. Absentee figures were provided by the LAUSD budget department. We assumed that enrollment was stable and students experienced the average absentee rate of their school of attendance. Incidence was calculated per 100 student-years.

\section{Analysis}

We calculated odds ratios using generalized estimating equations (GEE) models. Data were time stratified to adjust for time dependent exposures (age, school of enrollment). GEE regression accounted for dependence among repeated students nested within schools and thus controlled hierarchically for school of attendance. ${ }^{16-18}$ We imposed an autoregressive correlation structure since subjects closer in time are more likely correlated. The deviance test was employed to assess model fit. No interactions were added because of power limitations.

\section{RESULTS}

Of 6769 students enrolled into the study, 60\% ( $\mathrm{n}=4076)$ were boys and $40 \%(\mathrm{n}=2693)$ were girls (table 1$)$. Students were predominately Hispanic (61\%). Most students (45\%) had emotional/mental disabilities $(\mathrm{n}=3061), 19 \%$ had multiple disabilities $(\mathrm{n}=1304)$, and $18 \%$ were developmentally disabled $(n=1229)$. Fewer than $12 \%$ had physical disabilities $(\mathrm{n}=799)$, and $6 \%$ had other disabilities $(\mathrm{n}=376)$.
We identified 933 injury events, of which 236 were excluded (121 during summer sessions, two from the excluded medical school, 78 reports of general pain or no "visible injury", and 35 that did not link to school demographic data). A total of 697 events were analyzed.

\section{Injury rate}

The overall injury rate was 4.7/100 student-years (table 1 ). Rates were highest among students with multiple (6.4/100), other (6.2/100), and physical disabilities (5.3/100). Boys sustained about five injuries per 100 student-years, while girls suffered four injuries per 100 student-years. Black (6.1/ 100) and Hispanic students (4.6/100) had higher rates of injury than other race/ethnic groups. Rates generally increased with age.

\section{Injury types and body locations}

During the 697 injury events, students sustained 888 distinct physical insults to the body. A single region was affected during 547 events. The remaining 150 events resulted in multiple injuries either to the same or different body regions. Single and multiple injuries were collapsed across disability groups (table 2).

Most injuries were superficial bruises (28\%), cuts (28\%), and abrasions (18\%) (table 2). Unspecified wounds and bleeding made up almost $7 \%$ of injuries. Another $8 \%$ were "other" injuries (poisoning, insect bites, burns, dislocations, fractures, strains/sprains, foreign objects).

Forty eight percent of insults occurred to the face (table 2). The upper extremity (19\%) and head/neck (16\%) regions were also common locations. Fewer injuries were to the lower extremity (10\%). Injury types and body locations were similarly distributed across disability groups (results not shown).

\section{External cause}

About two thirds of injuries were either fall related (34\%) or involved other students biting, pushing, tripping, striking, or kicking the injured student (31\%) (table 3). Seventeen percent of cases collided into, were caught between, or cut by an object. About $12 \%$ of injuries involved various mechanisms, including seizures, self inflicted bites, headbangings, poisoning, contact with hot objects/fire, and foreign objects.

When causes were examined by disability, the emotionally/ mentally disabled suffered more injuries by other students $(38 \%)$ than from falls $(23 \%)$. In contrast, the developmentally disabled, multidisabled, and other disabled were injured more frequently from falls $(40 \%-44 \%)$ than by other students $(21 \%-34 \%)$. For the physically disabled, almost an equal number of students were injured from these two causes.

\section{School activity}

Only $60 \%$ of cases had complete information on school activity (table 3 ). Almost $27 \%$ were sports related, with twice as many injuries during organized play (physical education/ interscholastic sports $)(\mathrm{n}=125)$ than unorganized play (recess) $(n=62)$. Sixty six injuries $(10 \%)$ were sustained during class time. A remaining 22\% occurred during other activities: feeding, bus transportation or off-campus activity, passing period, and toileting/diaper/dress change.

Differential patterns were seen in specific disability groups. About a third of injuries to emotional/mental, physical, and multiple disabilities occurred during school related play (table 3). Students with developmental disabilities were injured more often during class time ( $11 \%$ ); only $8 \%$ of their injuries were sports related. 


\begin{tabular}{|c|c|c|c|c|}
\hline \multirow[b]{2}{*}{ Characteristic } & \multirow[b]{2}{*}{$\begin{array}{l}\text { Distribution in student } \\
\text { population: No (\%) }\end{array}$} & \multicolumn{3}{|c|}{ Rate estimation } \\
\hline & & $\begin{array}{l}\text { No of } \\
\text { injuries }\end{array}$ & Student-years* & $\begin{array}{l}\text { Injuries per } 100 \\
\text { student-years }\end{array}$ \\
\hline \multicolumn{5}{|l|}{ Disability } \\
\hline Developmental & 1229 (18.2) & 111 & 3021 & 3.7 \\
\hline Emotional/mental & 3061 (45.2) & 268 & 6511 & 4.1 \\
\hline Physical & $799(11.8)$ & 98 & 1844 & 5.3 \\
\hline Multiple & $1304(19.3)$ & 173 & 2720 & 6.4 \\
\hline Other & $376(5.6)$ & 47 & 756 & 6.2 \\
\hline \multicolumn{5}{|l|}{ Gender } \\
\hline Male & $4076(60.2)$ & 444 & 8817 & 5.0 \\
\hline Female & $2693(39.8)$ & 253 & 6034 & 4.2 \\
\hline \multicolumn{5}{|l|}{ Age (years) } \\
\hline $3-4$ & 954 (14.1) & 89 & 2212 & 4.0 \\
\hline $5-9$ & $2012(29.7)$ & 206 & 4351 & 4.7 \\
\hline $10-14$ & $1485(21.9)$ & 166 & 3636 & 4.6 \\
\hline $15-23$ & 2318 (34.2) & 236 & 4651 & 5.1 \\
\hline \multicolumn{5}{|l|}{ Race/ethnicity } \\
\hline Asian & $360(5.3)$ & 26 & 800 & 3.2 \\
\hline Black & $1380(20.4)$ & 173 & 2854 & 6.1 \\
\hline Hispanic & $4094(60.5)$ & 422 & 9216 & 4.6 \\
\hline Native American & $17(0.3)$ & 0 & 31 & - \\
\hline White & 918 (13.6) & 76 & 1950 & 3.9 \\
\hline Total & 6769 & 697 & 14851 & 4.7 \\
\hline
\end{tabular}

\section{School location}

More than $20 \%$ of all injuries occurred in the playground or on athletic fields (table 3 ). The next most common location was the classroom (13\%). Twenty five percent of injuries occurred in "other" locations including the auditorium/ gymnasium/cafeteria, bathroom/locker room, bus/bus loading area/lot, and hallway. Forty percent of cases had missing data on both external cause and school location.

Students with emotional/mental, physical, multiple, and other disabilities were injured most often in the playground/ athletic field. In contrast, those with developmental disabilities suffered more injuries in the classroom $(23 \%)$ than in the playground/athletic field (9\%).

\section{Measures of association}

Our final model included disability, gender, age, school, and year of enrollment. Including race/ethnicity did not improve fit $\left(\chi^{2}=3.29, p=0.35\right)$. Compared with developmentally disabled students, the odds of injury was increased among the multiple disabled (odds ratio (OR) 1.7, 95\% confidence interval (CI) 1.3 to 2.3 ), other disabled (OR $1.5,95 \%$ CI 1.0 to 2.3 ), and the physically disabled (OR $1.4,95 \%$ CI 1.0 to 1.9 ) (table 4). Males had a slightly increased odds compared with females (OR 1.2, 95\% CI 1.0 to 1.5). Associations between age and injury were weak and imprecise. Odds ratios from the

Table 2 Injury types and body locations, 1994-98 school years ( $n=888$ physical insults to the body); results are number $(\%)$

\begin{tabular}{|c|c|c|c|}
\hline \multicolumn{2}{|l|}{ Injury type } & \multicolumn{2}{|l|}{ Body locations } \\
\hline Abrasions & $161(18.1)$ & Head/neck & 142 (16.0) \\
\hline Bruises, pinches & $248(27.9)$ & Face & 428 (48.2) \\
\hline $\begin{array}{l}\text { Cuts, laceration, } \\
\text { punctures }\end{array}$ & $245(27.6)$ & $\begin{array}{l}\text { Chest/abdomen } \\
\text { contents }\end{array}$ & $14(1.5)$ \\
\hline $\begin{array}{l}\text { Unspecified wounds, } \\
\text { bleeding }\end{array}$ & $55(6.2)$ & Upper extremities & $171(19.3)$ \\
\hline Other & $67(7.5)$ & Lower extremities & $84(9.5)$ \\
\hline Unknown & $112(12.6)$ & $\begin{array}{l}\text { Not applicable/ } \\
\text { unknown }\end{array}$ & 49 (5.5) \\
\hline
\end{tabular}

GEE model were similar to estimates from conventional logistic models.

\section{DISCUSSION}

This is the first study to describe school related injury in a large population of over 6000 disabled students from multiple schools. Our estimated rate of $4.7 / 100$ is within the range reported in the general school population ( 1.67 to $7.45 / 100) .{ }^{19}$

Of all disabled groups, the multidisabled appear to be at greatest risk. Their combination of impairments that can occur in dyads, triunes, or greater forms could profoundly interfere with activities of daily living..$^{20}$ For example, a deaf mentally retarded child cannot process both auditory messages and visual hazards.

Those with physical disabilities also have an increased potential for injury. Other studies report the blind to be at high risk of pedestrian injuries and those with sensorimotor deficits at risk of burns. ${ }^{21}{ }^{22}$ Similarly at school, students with orthopedic handicaps may have difficulty using their limbs for balance to protect against falls. Visually impaired youth often cannot avoid collision hazards even with assistive devices. However, comparatively higher cognitive function may lead them to explore environments similarly to nondisabled children, providing more potential exposure to injury hazards.

Students with developmental disabilities have the weakest injury association. These students have substantial limitations in at least three major life activities (self care, language, learning, mobility, self direction, independent living, and economic sufficiency) and require special lifelong, coordinated care. $^{20}$ The developmentally disabled have limited physical movement and less contact with their classmates and hence participate in fewer school activities. Decreased exposure probably results in a lower injury risk.

Mental disabilities affect expectations of a child's behavioral, social, and functional capacity. ${ }^{23}$ Prior studies have reported high injury risk among those with behavioral problems. ${ }^{13}{ }^{14}$ Yet, in our study, students with mental/ emotional disabilities were at low risk of injury. Perhaps, despite cognitive limitations, these children may function at higher motor and sensory levels compared with their disabled peers and better handle physical hazards. Thus, physical 
Table 3 Primary external cause, school location, and school activity by disability, 1994-98 school years ( $\mathrm{n}=697$ injuries); results are number $(\%)$

\begin{tabular}{|c|c|c|c|c|c|c|}
\hline Disability & Developmental & Emotional/mental & Physical & Multiple & Other & Total \\
\hline \multicolumn{7}{|l|}{ Primary external cause } \\
\hline Falls & $45(40.5)$ & $63(23.4)$ & $36(36.4)$ & $75(43.9)$ & $20(42.6)$ & 239 (34.2) \\
\hline Injuries by other students & $23(20.7)$ & $101(37.5)$ & $32(32.3)$ & $41(24.0)$ & $16(34.0)$ & $213(30.6)$ \\
\hline $\begin{array}{l}\text { Collision with/caught between/ } \\
\text { cut by object }\end{array}$ & $14(12.6)$ & $67(24.9)$ & $13(13.1)$ & 21 (12.3) & $6(12.8)$ & $121(17.4)$ \\
\hline Other & $17(15.3)$ & $26(9.7)$ & 15 (15.2) & $19(11.1)$ & $3(6.4)$ & $80(11.5)$ \\
\hline Unknown & $12(10.8)$ & $12(4.5)$ & $3(3.0)$ & $15(8.8)$ & $2(4.3)$ & $44(6.3)$ \\
\hline \multicolumn{7}{|l|}{ School activity } \\
\hline Organized play & $4(3.6)$ & $52(19.3)$ & $26(26.3)$ & $37(21.6)$ & $6(12.8)$ & 125 (17.9) \\
\hline Unorganized play & $5(4.5)$ & $34(12.6)$ & $6(6.1)$ & $13(7.6)$ & $3(6.4)$ & $61(8.8)$ \\
\hline Class lesson/activity & $12(10.8)$ & $26(9.7)$ & $13(13.1)$ & $10(5.8)$ & $5(10.6)$ & $66(9.5)$ \\
\hline Other & $33(29.7)$ & $48(17.8)$ & $22(22.2)$ & $39(22.8)$ & 11 (23.4) & $153(22.0)$ \\
\hline Unknown & $57(51.4)$ & $109(40.5)$ & $32(32.3)$ & $72(42.1)$ & $22(46.8)$ & $292(41.8)$ \\
\hline \multicolumn{7}{|l|}{ School location } \\
\hline Playground/athletic field & $10(9.0)$ & $69(25.7)$ & 17 (17.2) & $34(19.9)$ & $16(34.0)$ & $146(20.9)$ \\
\hline Classroom & $26(23.4)$ & 36 (13.4) & $13(13.1)$ & $11(6.4)$ & $6(12.8)$ & $92(13.2)$ \\
\hline Other & $24(21.6)$ & $64(23.8)$ & $23(23.2)$ & $53(31.0)$ & $11(23.4)$ & $175(25.1)$ \\
\hline Unknown & $51(45.9)$ & $100(37.2)$ & $46(46.5)$ & $73(42.7)$ & $14(29.8)$ & $284(40.7)$ \\
\hline Total & 111 & 269 & 99 & 171 & 47 & 697 \\
\hline
\end{tabular}

aptitude, rather than mental processing, may most influence injury risk. Limited support of this hypothesis was found in a study of physical education among mentally retarded students. Students with low motor ability suffered substantially more injuries than students with average motor skill. ${ }^{24}$ Additional research is needed to further test how motor and mental functioning affect injury risk.

\section{Study limitations}

No national or international database on school related injuries exists. ${ }^{25}$ Like many existing school based studies, we are limited to data provided by single school districts maintained primarily to protect against litigation. Unfortunately, reporting biases may compromise the reliability and validity of school data. ${ }^{26}$

We compared injury rates across schools and found some differences which could reflect true rate differences or a reporting bias. Some variability is expected due to different definitions and reporting. For example, at one school, the nurse files all reports; in another school an administrator handles this responsibility. Without details about school specific procedures, we make no conclusions about the

Table 4 Odds ratios* (ORs) and confidence intervals (Cls) for injury, 1994-98 school years

\begin{tabular}{lll}
\hline & OR & $95 \% \mathrm{Cl}$ \\
\hline $\begin{array}{l}\text { Disability } \\
\text { Developmental }\end{array}$ & 1.0 & \\
Emotional/mental & 1.2 & 0.9 to 1.5 \\
$\begin{array}{l}\text { Physical } \\
\text { Multiple }\end{array}$ & 1.4 & 1.0 to 1.9 \\
Other & 1.7 & 1.3 to 2.3 \\
Gender & 1.5 & 1.0 to 2.3 \\
Female & 1.0 & \\
Male & 1.2 & 1.0 to 1.5 \\
Age (years) & & \\
3-4 & 1.0 & \\
5-9 & 1.2 & 0.9 to 1.6 \\
10-14 & 1.1 & 0.8 to 1.5 \\
15-23 & 1.1 & 0.8 to 1.5 \\
\hline
\end{tabular}

${ }^{*}$ GEE regression mutually adjusted for disability, gender, age, year, and school of enrollment on injury.

Autoregressive correlation structure.

Deviance test, comparing full versus nested model excluding race/ ethnicity: $\chi^{2}=3.29, p=0.35$.

Excludes Native Americans who had no reported injuries. degree of potential bias. At best, we hierarchically adjusted for unexplained variability by including schools as a variable in our GEE models.

Underreporting may still be problematic, although school policy requires reports for "all accidents however slight". Time constraints or other reasons may have prevented the filing of reports. We argue, however, that underreporting is probably less problematic in the disabled than the able bodied population. Because of their fragile health condition, special needs students are routinely screened by full time nurses. We suspect then that injuries at special schools are reported at a higher level and more consistently than in other school settings.

Despite this favorable situation, existing reports often lacked details on location and activity. Data may be missing because reports were not completed or no adults witnessed the event. For example, a non-verbal cognitively impaired student may present with a physical injury but cannot verbalize how or where the injury occurred. Or, injuries may have occurred in locations with more diffused adult supervision, such as during recess or in the playground. We found no significant missing data patterns across disability and demographics. Nonetheless, a concerted effort is needed for more thorough documentation of injuries at schools. Together schools and the research community should collaborate to build systematic injury data collection systems.

Another potential limitation of our study is our categorization of disability. Although groupings show some similarity in physical, mental and cognitive impairment, categories are admittedly heterogeneous with a wide range of conditions. For instance, the physically disabled could have cerebral palsy, skeletal disorders, muscular dystrophy, or visual impairment. ${ }^{23}$ Aggregating these children into one category may have pulled estimates towards the null value. A similar effect could have occurred within other disability categories. Without additional subjects and cases, separate examination of each disability was not feasible. We thus consulted with a special education specialist for expert advice. While categorization of disabilities is difficult in light of each child's unique condition, our groupings based on these impairments can still help determine appropriate activities and classroom placing (personal communication, Special Education Administrator, 2003). Our findings are thus a general picture of the injury experience within broad types of similar limiting characteristics and serve as a platform for more in-depth investigation. 
Migration and lost time from illness could also lead to biased rates. Children with disabilities typically remain at one school for several years, reducing the likelihood of migration (personal communication, Special Education Administrator, 1998). On the other hand, while average absenteeism was accounted, individual student absenteeism was unknown.

\section{IMPLICATIONS FOR PREVENTION}

In 2001, the Centers for Disease Control and Prevention (CDC) published recommendations for preventing unintentional injuries and violence in schools. CDC highlighted several areas including the social climate, physical environment, education, school health services, crisis response, and community integration. ${ }^{28}$ Some of these recommendations are currently being put into action throughout the United States. In New York City, Safety Makes Sense trains teachers, school personnel, and students in unintentional injury prevention..$^{29}$ In Arizona, PeaceBuilders fosters prosocial behavior through exercises among parents, students, teachers, administrators, and teachers to prevent violence in elementary schools. ${ }^{30}$ In California, the Department of Education published a resource guide listing several violence prevention programs delivered by classroom instruction. To our knowledge only PATHS in California, focused on violence prevention, has modules for children in special education (www.californiahealthykids.org, accessed 2003).

Many existing prevention programs may or may not be specified to special needs children. We take a first step by providing baseline scientific information about patterns of injury needed for assessing safety needs and structuring interventions. For example, a substantial number of bruises and cuts were reported to the face and head. To prevent these types of injuries, children with physical or multiple disabilities could wear protective headgear, like helmets, during sports or recreational play. Classrooms could also be designed with padding for edges and hard surfaces. Children with developmental disabilities, especially those prone to headbanging, may also benefit from helmet use in the classroom, where more of their injuries seem to occur. On the other hand, student-on-student injuries were most common among the emotionally/mentally disabled. School based conflict resolution measures are available and can be applied if tailored to the cognitive levels of students with mental disabilities. ${ }^{7}$ These are examples of what could be done in the special education environment.

But, before implementation, preventive measures should first incorporate a child's functional impairment and then be evaluated for appropriateness and effectiveness. ${ }^{7}$ For example, a safety education program for special needs children should include assessment, developing teaching and learning objectives, identifying the capability to learn, preparation, and teaching. ${ }^{31}$ If thoughtfully developed, such programs can significantly impact the care and management of injuries at school.

Public Health Law 99-457 stipulates that schools provide specialized health services to children with disabilities. ${ }^{32}$ School nurses focus primarily on tracheostomy management, ventilator monitoring, tube feeding, temperature control, catherization, and seizure management. ${ }^{23} 33$ The management of injuries is an area for further development but will require collective efforts among nurses, teachers, aides, administrators, and parents.

By creating a safer environment for all children, schools can better meet their educational goals. One goal is to teach children with disabilities life skills needed for social and physical integration into the community. Special education curriculum goes beyond academics and includes methods for student transitioning into society. Information about injury

\section{Key points}

- About five per 100 students with disabilities are injured each year at school. This rate is within the range reported for the able bodied school population.

- Students with multiple disabilities and physical disabilities may be at higher risk of injury compared with other disabled groups. Complex physical limitations may be an important contributory factor, but additional research is needed to assess how motor skill relates to injury.

- Those with multiple and physical disabilities sustained most of their injuries from falls during organized and unorganized sports activities in the playground or athletic fields. The developmentally disabled are injured often in the classroom. They are the lowest functioning and have limited exposure to physical activity.

- Information on school related injury patterns among children and adolescents with disabilities can help in their rehabilitation and integration into school and environments outside school.

patterns can help this process. By teaching children with disabilities how to navigate their school environment safely, they may be better equipped to manage physical challenges in the outside world.

\section{ACKNOWLEDGEMENTS}

We would like to acknowledge Arnold de Jesus, Becky Dobashi, MPH, and Elizabeth Tesh, MPH, for their assistance in data collection, entry, and processing. We also thank Steven Mark, William Renfroe, DrEd, Michelle Moutes, MA, Karen Hemmingway, Myrtice Adamson, Wayne Foglesong, and Russel Ung from the Los Angeles Unified School District. This research was supported by the Southern California Injury Prevention Research Center (CDC CCR 903622).

\section{Authors' affiliations}

M Ramirez, Division of Research on Children, Youth and Families, Childrens Hospital Los Angeles and the Southern California Injury Prevention Research Center, UCLA School of Public Health, Los Angeles, California

C Peek-Asa, lowa Injury Prevention Research Center, University of lowa College of Public Health, lowa City, lowa

J F Kraus, Southern California Injury Prevention Research Center, UCLA School of Public Health, Los Angeles, California

\section{REFERENCES}

1 Newacheck PW, Halfon N. Prevalence and impact of disabling chronic conditions in childhood. Am J Public Health 1998;88:610-7.

2 Garwood S. Educating young handicapped children: a developmental approach. 2nd Ed. Rockville, MD: Aspen Systems Corporation, 1983.

3 Aron L, Loprest P, Steuerle C. Serving children with disabilities: a systematic look at the programs. Washington, DC: Urban Institute Press, 1996.

4 Snyder T, Hoffman C. Digest of education statistics, 2001. Washington DC: National Center for Education Statistics, 2002 05/14/2002. Report No: NCES 2002130.

5 Bryan E, Warden M, Berg B, et al. Medical considerations for multihandicapped children in the public schools. J Sch Health 1978:48:84-9.

6 Dunne RG, Asher KN, Rivara FP. Injuries in young people with developmental disabilities: comparative investigation from the 1988 National Health Interview Survey. Ment Retard 1993;31:83-8.

7 Gaebler-Spira D, Thornton LS. Injury prevention for children with disabilities. Phys Med Rehabil Clin North Am 2002;13:891-906.

8 Children's Safety Network at Education Development Center, Inc. Injuries in the school environment: a resource guide. 2nd Ed. Newton, MA: Children's Safety Network at Education Development Center, Inc, 1997.

9 Woringer V. School accidents. Rev Med Suisse Romande 1995;115:153-6. 
10 Ohito FA, Opinya GN, Wang'ombe J. Traumatic dental injuries in normal and handicapped children in Nairobi, Kenya. East Afr Med J 1992;69:680-2.

11 Leland NL, Garrard J, Smith DK. Comparison of injuries to children with and without disabilities in a day-care center. J Dev Behav Pediatr 1994;15:402-8.

12 Berggreen SM. Accidents and surgical emergencies in a population of mentally retarded children. Acta Paediatr Scand 1972;62:289-96.

13 Sherrard J, Tonge BJ, Ozanne-Smith J. Injury in young people with intellectual disability: descriptive epidemiology. Inj Prev 2001;7:56-61.

14 Sherrard J, Tonge BJ, Ozanne-Smith J. Injury risk in young people with intellectual disability. J Intellect Disabil Res 2002;46:6-16.

15 Hinkle P. California special education programs - a composite of laws. Sacramento: California Department of Education, Special Education Division, 1999.

16 Rothman KJ, Greenland S. Modern epidemiology. Philadelphia: LippincottRaven Publishers, 1998.

17 Liang K, Zeger SL. Longitudinal data analysis using generalized linear models. Biometrika 1986;73:13-22.

18 Zeger SL, Liang K. Longitudinal data analysis for discrete and continuous outcomes. Biometrics 1986;42:121-30.

19 Gratz RR. School injuries: what we know, what we need. J Pediatr Health Care 1992;6:256-62.

20 Valletutti P. Introduction and overview. In: Valletutti P, Sims-Tucker B, eds. Severely and profoundly handicapped students. Baltimore, MD: Paul H Brookes, 1984

21 Roberts I, Norton R. Sensory deficit and the risk of pedestrian injury. Inj Prev 1995; 1:12-14.

22 Ramirez RJ, Behrends LG, Blakeney P, et al. Children with sensorimotor deficits: a special risk group. J Burn Care Rehabil 1998;19:124-7.
23 Burkett KW. Trends in pediatric rehabilitation. Nurs Clin North Am 1989;24:239-55.

24 Knowles CJ. The influence of a physical education program on the illness and accidents of mentally retarded students. Am Correct Ther J 1970;24:164-8.

25 US Congress, Office of Technology Assessment. Risks to students in school. Washington, DC: US Congress, Office of Technology Assessment, September, 1995.

26 Bremberg $\mathbf{S}$. Is school-based reporting of injuries at school reliable? A literature review and an empirical study. Accid Anal Prev 1989;21:183-9.

27 Rehm RS, Rohr JA. Parents', nurses', and educators' perceptions of risks and benefits of school attendance by children who are medically fragile/ technology-dependent. J Pediatr Nurs 2002;17:345-53.

28 Centers for Disease Control and Prevention. School health guidelines to prevent unintentional injuries and violence. MMWR Recomm Rep 2001:7(50(RR-22)):1-73.

29 De Simone Eichel J, Goldman L. Safety makes sense: a program to prevent unintentional injuries in New York City Public Schools. J Sch Health 2001;71:180-3.

30 Krug EG, Brener ND, Dahlberg $L$, et al. The impact of an elementary schoolbased violence prevention program on visits to the school nurse. Am J Prev Med 1997; 13:459-63.

31 Ricci F. Strategies for teaching safety education to children with special needs. Int J Trauma Nurs 2000;6:129-32.

32 Rodman J, Weill K, Driscoll M, et al. A nationwide survey of financing healthrelated services for special education students. J Sch Health 1999;69:133-9.

33 Wood SP, Walker DK, Gardner J. School health practices for children with complex medical needs. J Sch Health 1986;56:215-7.

\section{LACUNAE}

\section{Beware the arms race on our roads}

The rise of suburban four wheel drives has fuelled a fiery debate over road safety. Supporters claim one of the biggest attractions of these cars is their safety. Opponents contend that four wheel drives make the roads more dangerous for other drivers. Who is right? The answer, it seems, is both. According to a new report from the Monash Accident Research Centre, which analysed data from more than one million Australian crashes, four wheel drives reduce injury risk for their owners, and raise the risk to everyone else. From the perspective of their occupants, four wheel drives help save lives. By buying a four wheel drive instead of a medium sized car, your risk of death or serious injury in a crash falls by four in 1000 .

Next, the Monash researchers looked at the damage that different types of vehicles inflicted on other road users. If you crash after trading in your medium sized car for a four wheel drive, the chance that you will kill or badly injure the other driver increases by 11 in 1000 .

The net result? Four wheel drive buyers are making themselves safer, but the cost is being borne by other road users. For every serious injury or death that is saved by buying a four wheel drive, nearly three more result.

This simple statistic explains much of the rise in four wheel drive sales. With more four wheel drives on the road, other drivers begin to wonder whether they should buy one, too. In the US, this has led to the proliferation of larger and larger vehicles, in what University of California researcher Michelle White has dubbed "the arms race on American roads".

At the core of the problem is that four wheel drive owners do not appreciate the full costs that their vehicles impose on society. Our publicly funded healthcare system spreads the costs of hospital care across taxpayers, and in Victoria no-fault or partially no-fault insurance spreads the cost of accidents across all drivers.

An anomaly in Australia's tariff regime means four wheel drive buyers also benefit from a tariff rate $10 \%$ lower than the import duty on passenger cars-effectively a tax break for those who buy more dangerous vehicles. The solution? New four wheel drives should bear a tax equal to the difference between car tariffs and four wheel drive tariffs. And state governments should adjust vehicle registration taxes so four wheel drive owners pay the full cost that their vehicles impose on others.

One of the great successes in Australian public policy has been our ability to bring down the road toll. Thanks to random breath testing, seatbelt laws, airbags, and tough enforcement of speed limits, the fraction of the population killed on our roads each year is half what it was in 1985. By stemming the four wheel drive arms race, we can keep this deathly figure from rising again (contributed by Ian Scott; written by Andrew Leigh for The Age (Melbourne), July 2003). 